\title{
Review
}

Journal of Innate

Immunity
J Innate Immun 2011;3:274-279

DOI: $\underline{10.1159 / 000324176}$
Received: October 31, 2010

Accepted after revision: January 11, 2011

Published online: March 12, 2011

\section{Natural Killer Cell Responses to Viral Infection}

\author{
Joshua D. Brandstadter ${ }^{\mathrm{a}} \quad$ Yiping Yang ${ }^{\mathrm{a}, \mathrm{b}}$ \\ a Molecular Cancer Biology Program and ${ }^{b}$ Department of Medicine, Duke University Medical Center, \\ Durham, N.C., USA
}

\section{Key Words}

Natural killer cells • Viral infection · Innate immunity

\begin{abstract}
Natural killer (NK) cells, as part of the innate immune system, play a key role in host defense against viral infections. Recent advances have indicated that NK cell activation and function are regulated by the interplay between inhibitory and activating signals. Thus, a better understanding of mechanisms responsible for NK cell activation and function in the control of viral infections will help develop NK cell-based therapies. In this review, we will first discuss how NK cells are activated in response to viral infections. We will then focus on the recruitment of activated NK cells to the site of infection as well as on NK cell effector mechanisms against virally infected cells.

Copyright ๑ 2011 S. Karger AG, Basel
\end{abstract}

\section{Introduction}

Natural killer (NK) cells are unique lymphocytes without a clonally specific receptor [1]. As lymphocytes of the innate immune system, NK cells lack antigen-specific receptors and do not resemble $\mathrm{T}$ and $\mathrm{B}$ cells. This identity contributed to speculation that NK cells, origi- nally discovered through their ability to destroy tumor cells without prior sensitization, mediate cytolysis in a nonspecific fashion $[2,3]$. Subsequent observations that NK cells can kill certain tumor cells without major histocompatibility complex (MHC) class I [4] has led to the 'missing self' hypothesis, which proposes MHC class I functions as a ligand for inhibitory receptors in NK cellmediated cytolysis. It is now better understood that the activation of NK cells and their functions are regulated by both activating and inhibitory signals.

While initial work demonstrated their antitumor activities, NK cells are also critical for the control of certain infections, particularly viral infections. In humans, NK cells are important to the innate immune response against members of the herpesvirus, poxvirus and papillomavirus families [5, 6]. Patients with identified NK cell deficiencies are predisposed to particularly severe, recurrent viral infections. Mouse models provide additional evidence that NK cells give critical help to control several viral infections, most notably murine cytomegalovirus (MCMV), poxviruses and influenza $[7,8]$.

In this review, we will detail how NK cells are activated in response to viral infections. We will then proceed to describe the recruitment of activated NK cells to the site of infection and NK cell effector mechanisms against virally infected cells.

\section{KARGER}

Fax +4161306 1234

E-Mail karger@karger.ch

www.karger.com
(C) 2011 S. Karger AG, Basel

Accessible online at: www.karger.com/jin
Dr. Yiping Yang

Department of Medicine

Duke University Medical Center

Box 103005, Durham, NC 27710 (USA)

Tel. +1 919668 0932, E-Mail yang0029@mc.duke.edu 


\section{NK Cell Activation in Response to Viral Infection}

\section{NK Cell-Activating Receptors}

The 'missing self' hypothesis predicted the mechanism whereby NK cells destroy virus-infected cells that have a downregulated expression of MHC class I. However, in many circumstances, NK cells can efficiently eliminate virus-infected cells that maintain expression of the inhibitory MHC class I $[9,10]$. Recent advances have indicated that NK cell activation and function are regulated by the interplay between the inhibitory and activating receptors [11, 12]. Indeed, accumulating evidence has revealed the importance of NK cell-activating receptors in antiviral defense.

The first NK cell-activating receptor identified to be critical for viral control in vivo was $\mathrm{Ly} 49 \mathrm{H}$, which is necessary to clear MCMV infection [13]. Ly49H, a C-type lectin-like receptor, specifically recognizes the m157 open reading frame of MCMV. This ligand was identified by two independent groups using heterologous reporter cells exposed to MCMV-infected cells [14, 15]. Activation of Ly49H by $\mathrm{m} 157$ is required for NK cell-mediated clearance in MCMV-resistant mice. Deletion of the genetic locus of Ly49H, Cmv1 ${ }^{r}$, or use of Ly49H-blocking antibodies confers susceptibility to the virus [16]. Deletion of $\mathrm{m} 157$ also facilitates viral escape and persistence later in the infection. The Ly49 lectin-like receptors do not exist in humans. However, structurally different killer immunoglobulin-like receptors (KIRs) function similarly and recognize peptide-loaded MHC class I molecules. Patients homozygous for KIR2DL3 or KIR3DS1 and particular human leukocyte antigen haplotypes are much more likely to clear acute hepatitis $\mathrm{C}$ virus rather than progress to chronic infection [10]. KIR2DS1 can activate NK cells by recognizing MHC class I molecules loaded with peptide during Epstein-Barr virus infection [9].

The natural cytotoxicity receptors represent another class of activating receptors that recognize viral-derived products [17]. In humans, there are three members of this receptor family: NKp30, NKp44 and NKp46. Of these, NKp46 is the most prominent and is found on all NK cells. NKp46 recognizes hemagglutinin of influenza virus and hemagglutinin-neuraminidase of parainfluenza virus, suggesting that it may be involved in resistance to these viruses [17]. Indeed, mice deficient in NCR1, a murine homolog of NKp46, fail to protect against lethal influenza infection [18]. NKp46 and another activating receptor, DNAM-1, are critical for activation in response to human CMV-infected myeloid dendritic cells; however, a cellular ligand for NKp46 remains to be identified [19].
Besides direct recognition of viral-derived products or viral peptide-loaded MHC molecules, NK cells can also recognize stress-induced ligands through the NKG2 family, most notably the NKG2D receptor [20]. NKG2D, a C-type lectin-like homodimer, promotes NK cell activation by recognizing host stress proteins induced upon viral infections. The stress-induced NKG2D ligands are Rae-1, Mult-1 and H60 classes in mice and the ULBP and MIC classes in humans. Stress ligands have been shown to play an important role in the control of human CMV and MCMV infections [21, 22]. NKG2D is also critical in NK cell-mediated control of infection with vaccinia virus [23] and adenovirus [24]. The importance of NKG2D in viral defense is highlighted by the viral evasion mechanisms that seem to escape NKG2D recognition [25]. It has been shown that MCMV can downregulate H60 to evade NK cell-mediated clearance and that human CMV can produce antagonists to directly block NKG2D recognition of ULBP. The expression of NKG2D ligands on accessory cells such as dendritic cells and macrophages also mediates 'crosstalk' with NK cells. One recent study described a pathway in which lipopolysaccharide treatment of macrophages upregulated MICA expression by increasing its transcription, promoting its translational or posttranslational processing, and downregulating micro-RNAs that target MICA [26].

Downstream of these activating receptors, ligand recognition triggers an intracellular kinase cascade to transmit the activation signal [11]. This cascade begins with Src tyrosine kinase phosphorylation of the immunoreceptor tyrosine-based activation motifs (ITAMs), which are found on adaptor subunits KARAP/DAP-12, FceRI $\gamma$ and CD3 $\zeta$. The phosphorylated ITAMs then recruit tandem SH2 tyrosine kinases Syk and ZAP70, which propagate a phosphorylation signaling cascade through transmembrane and cytosolic adaptors similar to T/B-cell receptor signaling in fellow lymphocytes. Ultimate downstream activation pathways include PI3K/ERK, Ras/ERK and PLC $\gamma / D A G / \mathrm{IP}_{3}$. Importantly, NKG2D signaling differs from the traditional ITAM activation pathway. In humans, NKG2D relies on DAP-10 to transmit its activation signal, unlike other activating receptors that signal through DAP-12. DAP-10 requires the PI3K signaling pathway, which it activates via phosphorylation cascades involving either the $\mathrm{p} 85$ subunit of PI3K, Grb2 directly or the Sos1-Vav1-Grb2 complex [27]. Recent studies have shown that NKG2D signaling alone is not sufficient to activate NK cells and that efficient NK cell activation requires cooperation of other activating receptors acting synergistically [28]. In mice, NKG2D can signal through 
both DAP-10 and DAP-12, leading to NK cell activation $[29,30]$.

In addition to $\mathrm{NK}$ cell-activating receptors, direct Toll-like receptor (TLR) stimulation on NK cells has emerged to play an important role in NK cell activation. It has been shown that TLR3, TLR7, TLR8 and TLR9 are expressed on human NK cells and that ligands for these TLRs can activate human NK cells in vitro [31-33]. Intranasally administered $\mathrm{CpG}$ can in fact activate and recruit NK cells to the lung [34]. Recent studies have demonstrated that direct TLR2 stimulation on murine NK cells is critical for their activation and function in the control of vaccinia viral infection in vivo [23]. This is achieved by activating the downstream MyD88-PI3K-ERK pathway. Similarly, direct activation of TLR4 by a bacterial component fimbrial protein, FimH, appears to be important for the activation of both mouse and human NK cells [35].

\section{NK Cell Inhibitory Receptors}

To control inappropriate activating signals, there is a repertoire of inhibitory receptors that repress NK cell activation [36]. These include lectin-like heterodimers such as CD94-NKG2A [37], KIRs found in humans [38] or lectin-like Ly49 homodimers found in mice [39]. These inhibitory receptors survey MHC class I molecules and seem to protect healthy cells from inappropriate NK cellmediated killing. The ability of KIRs and Ly49 homodimers to be either activating or inhibitory while recognizing class I MHC molecules is dependent on the specific receptors' downstream signaling and the different human leukocyte antigen subtypes they recognize. Some inhibitory receptors also recognize other ligands such as cadherins and collagen. Despite the structural differences between the lectin and immunoglobulin receptors, these classes of receptors signal downstream similarly.

The balance between activating and inhibitory receptors is achieved within the cell, downstream of receptorligand binding [36]. Contradictory signaling between the activating and inhibitory receptors depends on the ITAMs and immunoreceptor tyrosine-based inhibition motifs (ITIMs), respectively. Upon stimulation of inhibitory receptors, ITIMs on the cytosolic domains of inhibitory receptors become phosphorylated by Src kinases. Phosphorylated ITIMs activate phosphatases to counter the kinase cascade of the activating receptors. They can recruit SHP-1 and SHP-2 protein phosphatases and SHIP1, a lipid phosphatase, which dephosphorylate many downstream molecules in the activation signaling pathway to dampen $\mathrm{Ca}^{2+}$ influx and effector function. Only Vav1, a guanine nucleotide exchange factor for Rac1, has emerged as a direct SHP-1 substrate from a 'functional substrate trapping' screen that employed a catalytically inactive KIR2DL1-SHP-1 chimera [40]. Dephosphorylation of Vav1 may prevent its promotion of Racl remodeling of the actin cytoskeleton for cell cytotoxicity.

The model for integration of inhibitory and activating signaling has progressed further with the identification of subsets of 'unlicensed' NK cells in mice [41]. These 'unlicensed' cells lack any known inhibitory receptor, but are apparently self-tolerant and hyporesponsive upon ligation of activating receptors in vitro. This important finding followed work characterizing the hyporesponsiveness of NK cells from MHC class-I-deficient mice. The hyporesponsiveness could be reversed only in NK cells expressing inhibitory receptors capable of binding the particular class I MHC allele reintroduced [42]. However, a more recent study indicates that only 'unlicensed' NK cells are capable of mediating MCMV control in vivo [43], suggesting that $\mathrm{NK}$ cells lacking inhibitory receptors may be critical for NK cell control of certain infections.

\section{Cytokines Involved in NK Cell Activation}

In addition to direct stimulation through activating receptors, NK cells can be activated by cytokines during the initial stages of viral infection [44]. Cytokines can also enhance activating receptor-mediated NK cell activation. The four principal cytokines involved in NK cell activation are type I interferons (IFNs), interleukin (IL)12, IL-15 and IL-18. These cytokines can be produced directly by infected cells, or by activated dendritic cells or macrophages [45].

Type I IFNs, which include over a dozen different subtypes of IFN- $\alpha$ and one IFN- $\beta$, signal through IFN- $\alpha / \beta$ $\mathrm{R} 1$ and IFN- $\alpha / \beta$ R2 [46]. They directly activate NK cells to enhance cell-mediated cytotoxicity. This role of type I IFNs has been well established in the setting of infection with MCMV, lymphocytic choriomeningitis virus (LCMV) and several other viruses. They can also induce secretion of IL-15, a cytokine capable of inducing NK cell proliferation.

Unlike type I IFNs, IL-12 activates NK cells to augment the production of IFN- $\gamma$ [47]. IL-12 is produced in response to MCMV infection and is capable of activating NK cells alone. In LCMV infection, the absence of high levels of IL-12 likely account for the weak NK cell response. Herpes simplex virus (HSV) provokes robust IL12 and type I IFN responses in both mice and humans, whereas patients with HIV show little IL-12 response, which correlates to the degree of NK cell activation, respectively [8]. Another cytokine, IL-18, can also induce 
IFN- $\gamma$ production by NK cells [48]. IL-18 has been shown in at least one setting to act synergistically with IL-12 in its ability to induce IFN- $\gamma$ expression in NK cells. Both IL-12 and IL-18 appear necessary to prime NK cells in response to viral infection. The mechanism of this priming is not entirely clear, but involves increasing translation of IFN- $\gamma$ mRNA.

Cytokine receptors signal through the JAK-STAT pathway to induce NK cell activation [46]. Seven members of the STAT family facilitate the differential effects of various cytokines. Type I IFNs, for example, induce phosphorylation of STAT1 and STAT2 for STAT1-STAT2 heterodimers and STAT1 homodimers to drive gene expression that enhances cell cytotoxicity [49]. IL-15 also uses STAT1 to trigger NK cell proliferation. STAT1, on the other hand, impairs IL-12 sensitivity and IFN- $\gamma$ production. Instead, STAT4 drives IFN- $\gamma$ production in response to IL-12. The regulation of STAT molecules has clear consequences for cytokine signaling, and loss of STAT molecules can increase viral sensitivity at early times after infection.

\section{NK Cell Recruitment to the Site of Infection}

Viral control necessitates not just appropriate NK cell activation, but also effective recruitment of activated NK cells to the site of infection [50]. In the steady state, NK cells can be found in the spleen, lung, bone marrow, lymph nodes, peripheral blood mononuclear cells, and liver. Sphingosine-1-phosphate plays an important role in lymphocyte migration, and S1P5R, a G-protein-coupled receptor (GPCR), is differentially expressed on NK cells to control their movement in development and the steady state [51].

During infection, NK cells migrate towards and accumulate at the sites of infection for a wide range of viruses, including LCMV, MCMV, mouse hepatitis virus and vaccinia virus [52]. Broadly, four chemokine receptors have been implicated in NK cell recruitment to sites of inflammation: CCR2, CCR5, CXCR3 and $\mathrm{CX}_{3} \mathrm{CR} 1$ [50]. All except $\mathrm{CX}_{3} \mathrm{CR} 1$ have been shown to play a role in chemotaxis to sites of viral infection. Specifically, CCR2 and CCR5 are critical for trafficking to the liver in MCMV infection $[53,54]$. CCR 5 also induces NK cell recruitment to the central nervous system during HSV-2 infection [55]. CXCR3 aids NK cell movement to the liver in the setting of Dengue virus infection and, along with CD62L, generally facilitates migration to the lymph nodes in inflammation $[50,56]$.

NK Cells in Viral Control
However, the mechanisms of NK cell migration are only beginning to become understood. NK cell migration to chemokines in vitro or to the peritoneum of mice intraperitoneally infected with vaccinia virus has been shown to be pertussin-toxin sensitive, suggesting a role for GPCRs $[57,58]$. The PI3K pathway, specifically the p110 $\gamma$ and p110 $\delta$ isoforms, plays a role in the motility of leukocytes in general. NK cell migration is similarly controlled by these two PI3K isoforms where p110 $\gamma$ signals downstream of GPCRs in response to chemokines and p110 functions downstream of tyrosine kinase-linked receptors in response to other steady-state or inflammatory signals [57]. However, the role of these PI3K isoforms in NK cell trafficking in response to viral infection has not yet been investigated.

\section{NK Cell Effector Responses to Virally Infected Cells}

Upon activation and recruitment to the site of infection, NK cells employ three main strategies to kill virally infected cells: the production of cytokines, the secretion of cytolytic granules, and the use of death receptor-mediated cytolysis [8]. Production of IFN- $\gamma$ is an important effector function of activated NK cells. IFN- $\gamma$ exerts direct effects in making host cells less hospitable to the virus and can act distally to prevent infection in other cells. It also recruits and activates other effector leukocytes, including cytotoxic $\mathrm{T}$ lymphocytes and $\mathrm{CD} 4^{+} \mathrm{T}$ helper type 1 cells [59]. NK cell production of IFN- $\gamma$ helps to control MCMV. Mice with deficiencies in IFN- $\gamma$ or IFN- $\gamma$ R are increasingly susceptible to vaccinia virus, HSV and other viral infections. Similar susceptibilities are seen in humans with identified IFN- $\gamma$ or IFN- $\gamma \mathrm{R}$ deficiencies [60].

NK cells, called 'large granular lymphocytes' in early work, can also directly kill infected cells by mediating cytolysis through preformed granules $[8,52]$. These granules, notably perforin and granzymes, are similar to those used by cytotoxic $\mathrm{T}$ lymphocytes and function after direct interaction between the NK and infected cells. Perforin, a membrane pore-forming molecule, can permeabilize the cell [61]. On the other hand, granzymes, a family of serine proteases, disrupt cell cycle progression, inflict DNA damage and dissolve the nucleus upon entrance into the cell. Humans with identified deficiencies in perforin are susceptible to herpesvirus infections, and perforin knockout mice have impaired clearance of MCMV, influenza and several other viruses $[5,8]$.

FasL and tumor-necrosis factor-related apoptosis-inducing ligand can also be used in NK cell-mediated cy- 
tolysis of infected cells [62]. In these pathways, NK cells express ligands capable of activating death receptors on the target cell that can trigger the extrinsic pathway of apoptosis. Tumor-necrosis factor-related apoptosis-inducing ligand-mediated cytotoxicity is particularly important for immature NK cells, which cannot use perforin-dependent mechanisms [62].

\section{Concluding Remarks}

In this review, we have sought to illustrate the role of NK cells in viral control. We have described the mechanisms of their activation, recruitment and effector responses against virally infected cells. Research on their response to viruses has demonstrated that NK cells are not the unbridled, non-MHC-restricted killers they were originally depicted to be. Instead, their activation and function are highly regulated. How NK cells respond to particular viral infections is of continuing interest in the development of new treatment options. Specifically, delineating the key signaling pathways in the activation and migration of NK cells in response to particular infections remains an essential avenue of future research necessary for the development of future NK cell-based therapies.

\section{Acknowledgements}

This work was supported by the National Institutes of Health grants AI083000, CA136934, CA047741, CA111807, and an Alliance for Cancer Gene Therapy grant.

\section{References}

$\checkmark 1$ Cerwenka A, Lanier LL: Natural killer cells, viruses and cancer. Nat Rev Immunol 2001; 1:41-49.

2 Kiessling R, Klein E, Wigzell H: 'Natural' killer cells in the mouse. 1. Cytotoxic cells with specificity for mouse moloney leukemia cells. Specificity and distribution according to genotype. Eur J Immunol 1975;5:112-117.

-3 Herberman RB, Nunn ME, Lavrin DH: Natural cytotoxic reactivity of mouse lymphoid cells against syngeneic acid allogeneic tumors. 1. Distribution of reactivity and specificity. Int J Cancer 1975;16:216-229.

4 Karre K, Ljunggren HG, Piontek G, Kiessling $\mathrm{R}$ : Selective rejection of H-2-deficient lymphoma variants suggests alternative immune defence strategy. Nature 1986;319:675-678.

5 Orange JS: Human natural killer cell deficiencies and susceptibility to infection. Microbes Infect 2002;4:1545-1558.

6 Biron CA, Byron KS, Sullivan JL: Severe herpesvirus infections in an adolescent without natural killer cells. N Engl J Med 1989;320: 1731-1735.

7 Bukowski JF, Woda BA, Habu S, Okumura K, Welsh RM: Natural killer cell depletion enhances virus synthesis and virus-induced hepatitis in vivo. J Immunol 1983;131:1531-1538.

8 Lee SH, Miyagi T, Biron CA: Keeping NK cells in highly regulated antiviral warfare. Trends Immunol 2007;28:252-259.

-9 Stewart CA, Laugier-Anfossi F, Vely F, Saulquin X, Riedmuller J, Tisserant A, Gauthier L, Romagne F, Ferracci G, Arosa FA, Moretta A, Sun PD, Ugolini S, Vivier E: Recognition of peptide-MHC class I complexes by activating killer immunoglobulin-like receptors. Proc Natl Acad Sci USA 2005; 102: 13224-13229.
10 Khakoo SI, Carrington M: KIR and disease: a model system or system of models? Immunol Rev 2006;214:186-201.

11 Lanier LL: Up on the tightrope: natural killer cell activation and inhibition. Nat Immunol 2008;9:495-502.

12 Bryceson YT, Ljunggren HG, Long EO: Minimal requirement for induction of natural cytotoxicity and intersection of activation signals by inhibitory receptors. Blood 2009; 114:2657-2666.

13 Brown MG, Dokun AO, Heusel JW, Smith HR, Beckman DL, Blattenberger EA, Dubbelde CE, Stone LR, Scalzo AA, Yokoyama WM: Vital involvement of a natural killer cell activation receptor in resistance to viral infection. Science 2001;292:934-937.

14 Smith HR, Heusel JW, Mehta IK, Kim S, Dorner BG, Naidenko OV, Iizuka K, Furukawa H, Beckman DL, Pingel JT, Scalzo AA, Fremont DH, Yokoyama WM: Recognition of a virus-encoded ligand by a natural killer cell activation receptor. Proc Natl Acad Sci USA 2002;99:8826-8831.

15 Arase H, Mocarski ES, Campbell AE, Hill $A B$, Lanier LL: Direct recognition of cytomegalovirus by activating and inhibitory NK cell receptors. Science 2002;296:13231326.

16 French AR, Yokoyama WM: Natural killer cells and viral infections. Curr Opin Immunol 2003;15:45-51.

17 Mandelboim O, Lieberman N, Lev M, Paul L, Arnon TI, Bushkin Y, Davis DM, Strominger JL, Yewdell JW, Porgador A: Recognition of haemagglutinins on virus-infected cells by NKp46 activates lysis by human NK cells. Nature 2001;409:1055-1060.
18 Gazit R, Gruda R, Elboim M, Arnon TI, Katz G, Achdout H, Hanna J, Qimron U, Landau G, Greenbaum E, Zakay-Rones Z, Porgador A, Mandelboim O: Lethal influenza infection in the absence of the natural killer cell receptor gene Ncrl. Nat Immunol 2006;7: 517-523.

19 Magri G, Muntasell A, Romo N, Saez-Borderias A, Pende D, Geraghty DE, Hengel H, Angulo A, Moretta A, Lopez-Botet M: NKp46 and DNAM-1 NK cell receptors drive the response to human cytomegalovirus infected myeloid dendritic cells overcoming viral immune evasion strategies. Blood 2011;117: 848-856. DOI: blood-2010-08-301374.

20 Jamieson AM, Diefenbach A, McMahon CW, Xiong N, Carlyle JR, Raulet DH: The role of the NKg2d immunoreceptor in immune cell activation and natural killing. Immunity 2002;17:19-29.

21 Guma M, Angulo A, Lopez-Botet M: NK cell receptors involved in the response to human cytomegalovirus infection. Curr Top Microbiol Immunol 2006;298:207-223.

22 Andoniou CE, van Dommelen SL, Voigt V, Andrews DM, Brizard G, Asselin-Paturel C, Delale T, Stacey KJ, Trinchieri G, Degli-Esposti MA: Interaction between conventional dendritic cells and natural killer cells is integral to the activation of effective antiviral immunity. Nat Immunol 2005;6:1011-1019.

-23 Martinez J, Huang X, Yang Y: Direct TLR2 signaling is critical for NK cell activation and function in response to vaccinia viral infection. PLoS Pathog 2010;6:e1000811.

24 Zhu J, Huang X, Yang Y: NKG2D is required for NK cell activation and function in response to E1-deleted adenovirus. J Immunol 2010;185:7480-7486. 
$\longrightarrow 25$ Orange JS, Fassett MS, Koopman LA, Boyson JE, Strominger JL: Viral evasion of natural killer cells. Nat Immunol 2002;3:10061012.

-26 Eissmann P, Evans JH, Mehrabi M, Rose EL, Nedvetzki S, Davis DM: Multiple mechanisms downstream of TLR-4 stimulation allow expression of NKG2D ligands to facilitate macrophage/NK cell crosstalk. J Immunol 2010;184:6901-6909.

27 Giurisato E, Cella M, Takai T, Kurosaki T, Feng Y, Longmore GD, Colonna M, Shaw AS: Phosphatidylinositol 3-kinase activation is required to form the NKG2D immunological synapse. Mol Cell Biol 2007;27:85838599.

$\longrightarrow 28$ Bryceson YT, March ME, Ljunggren HG, Long EO: Synergy among receptors on resting NK cells for the activation of natural cytotoxicity and cytokine secretion. Blood 2006;107:159-166.

-29 Gilfillan S, Ho EL, Cella M, Yokoyama WM, Colonna M: NKG2D recruits two distinct adapters to trigger NK cell activation and costimulation. Nat Immunol 2002;3:11501155.

-30 Diefenbach A, Tomasello E, Lucas M, Jamieson AM, Hsia JK, Vivier E, Raulet DH: Selective associations with signaling proteins determine stimulatory versus costimulatory activity of NKG2D. Nat Immunol 2002;3: 1142-1149.

- 31 Sivori S, Falco M, Della Chiesa M, Carlomagno S, Vitale M, Moretta L, Moretta A: $\mathrm{CpG}$ and double-stranded RNA trigger human NK cells by Toll-like receptors: induction of cytokine release and cytotoxicity against tumors and dendritic cells. Proc Natl Acad Sci USA 2004;101:10116-10121.

- 32 Schmidt KN, Leung B, Kwong M, Zarember KA, Satyal S, Navas TA, Wang F, Godowski PJ: APC-independent activation of NK cells by the Toll-like receptor 3 agonist doublestranded RNA. J Immunol 2004;172:138143.

-33 Hart OM, Athie-Morales V, O'Connor GM, Gardiner CM: TLR7/8-mediated activation of human NK cells results in accessory celldependent IFN-gamma production. J Immunol 2005;175:1636-1642.

34 Pesce I, Monaci E, Muzzi A, Tritto E, Tavarini S, Nuti S, De Gregorio E, Wack A: Intranasal administration of $\mathrm{CpG}$ induces a rapid and transient cytokine response followed by dendritic and natural killer cell activation and recruitment in the mouse lung. J Innate Immun 2010;2:144-159.

-35 Mian MF, Lauzon NM, Andrews DW, Lichty BD, Ashkar AA: FimH can directly activate human and murine natural killer cells via TLR4. Mol Ther 2010;18:1379-1388.

-36 Long EO: Negative signaling by inhibitory receptors: the NK cell paradigm. Immunol Rev 2008;224:70-84.
Moretta L, Ciccone E, Mingari MC, Biassoni $\mathrm{R}$, Moretta A: Human natural killer cells: origin, clonality, specificity, and receptors. Adv Immunol 1994;55:341-380.

38 Wagtmann N, Rajagopalan S, Winter CC, Peruzzi M, Long EO: Killer cell inhibitory receptors specific for HLA-C and HLA-B identified by direct binding and by functional transfer. Immunity 1995;3:801-809.

39 Karlhofer FM, Ribaudo RK, Yokoyama WM: MHC class I alloantigen specificity of Ly-49+ IL-2-activated natural killer cells. Nature 1992;358:66-70.

40 Stebbins CC, Watzl C, Billadeau DD, Leibson PJ, Burshtyn DN, Long EO: Vavl dephosphorylation by the tyrosine phosphatase SHP-1 as a mechanism for inhibition of cellular cytotoxicity. Mol Cell Biol 2003;23: 6291-6299.

-41 Fernandez NC, Treiner E, Vance RE, Jamieson AM, Lemieux S, Raulet DH: A subset of natural killer cells achieves self-tolerance without expressing inhibitory receptors specific for self-MHC molecules. Blood 2005; 105:4416-4423.

42 Kim S, Poursine-Laurent J, Truscott SM, Lybarger L, Song YJ, Yang L, French AR, Sunwoo JB, Lemieux S, Hansen TH, Yokoyama WM: Licensing of natural killer cells by host major histocompatibility complex class I molecules. Nature 2005;436:709-713.

43 Orr MT, Murphy WJ, Lanier LL: 'Unlicensed' natural killer cells dominate the response to cytomegalovirus infection. Nat Immunol 2010;11:321-327.

44 Dokun AO, Kim S, Smith HR, Kang HS, Chu DT, Yokoyama WM: Specific and nonspecific NK cell activation during virus infection. Nat Immunol 2001;2:951-956.

45 Nguyen KB, Salazar-Mather TP, Dalod MY, Van Deusen JB, Wei XQ, Liew FY, Caligiuri MA, Durbin JE, Biron CA: Coordinated and distinct roles for IFN-alpha beta, IL-12, and IL-15 regulation of NK cell responses to viral infection. J Immunol 2002;169:4279_ 4287.

46 Garcia-Sastre A, Biron CA: Type 1 interferons and the virus-host relationship: a lesson in detente. Science 2006;312:879-882.

$\checkmark 4$ Orange JS, Biron CA: An absolute and restricted requirement for IL-12 in natural killer cell IFN-gamma production and antiviral defense. Studies of natural killer and T cell responses in contrasting viral infections. J Immunol 1996;156:1138-1142.

48 Gherardi MM, Ramirez JC, Esteban M: IL-12 and IL-18 act in synergy to clear vaccinia virus infection: involvement of innate and adaptive components of the immune system. J Gen Virol 2003;84:1961-1972.

49 Nguyen KB, Cousens LP, Doughty LA, Pien GC, Durbin JE, Biron CA: Interferon alpha/ beta-mediated inhibition and promotion of interferon gamma: STAT1 resolves a paradox. Nat Immunol 2000;1:70-76.
50 Gregoire C, Chasson L, Luci C, Tomasello E, Geissmann F, Vivier E, Walzer T: The trafficking of natural killer cells. Immunol Rev 2007;220:169-182.

51 Walzer T, Chiossone L, Chaix J, Calver A, Carozzo C, Garrigue-Antar L, Jacques Y, Baratin M, Tomasello E, Vivier E: Natural killer cell trafficking in vivo requires a dedicated sphingosine 1-phosphate receptor. Nat Immunol 2007;8:1337-1344.

52 Natuk RJ, Welsh RM: Accumulation and chemotaxis of natural killer/large granular lymphocytes at sites of virus replication. J Immunol 1987;138:877-883.

53 Salazar-Mather TP, Orange JS, Biron CA: Early murine cytomegalovirus (MCMV) infection induces liver natural killer (NK) cell inflammation and protection through macrophage inflammatory protein lalpha (MIP1alpha)-dependent pathways. J Exp Med 1998;187:1-14.

54 Hokeness KL, Kuziel WA, Biron CA, Salazar-Mather TP: Monocyte chemoattractant protein-1 and CCR2 interactions are required for IFN-alpha/beta-induced inflammatory responses and antiviral defense in liver. J Immunol 2005;174:1549-1556.

55 Thapa M, Kuziel WA, Carr DJ: Susceptibility of CCR5-deficient mice to genital herpes simplex virus type 2 is linked to NK cell mobilization. J Virol 2007;81:3704-3713.

56 Chen JP, Lu HL, Lai SL, Campanella GS, Sung JM, Lu MY, Wu-Hsieh BA, Lin YL, Lane TE, Luster AD, Liao F: Dengue virus induces expression of CXC chemokine ligand 10/IFN-gamma-inducible protein 10 , which competitively inhibits viral binding to cell surface heparan sulfate. J Immunol 2006;177:3185-3192.

57 Saudemont A, Garcon F, Yadi H, Roche-Molina M, Kim N, Segonds-Pichon A, MartinFontecha A, Okkenhaug K, Colucci F: p110gamma and p110delta isoforms of phosphoinositide 3-kinase differentially regulate natural killer cell migration in health and disease. Proc Natl Acad Sci USA 2009;106: 5795-5800.

58 Prlic M, Gibbs J, Jameson SC: Characteristics of NK cell migration early after vaccinia infection. J Immunol 2005; 175:2152-2157.

59 Lee SH, Biron CA: Here today - not gone tomorrow: roles for activating receptors in sustaining NK cells during viral infections. Eur J Immunol 2010;40:923-932.

60 Novelli F, Casanova JL: The role of IL-12, IL23 and IFN-gamma in immunity to viruses. Cytokine Growth Factor Rev 2004;15:367377.

-61 Tay CH, Welsh RM: Distinct organ-dependent mechanisms for the control of murine cytomegalovirus infection by natural killer cells. J Virol 1997;71:267-275.

62 Colucci F, Caligiuri MA, Di Santo JP: What does it take to make a natural killer? Nat Rev Immunol 2003;3:413-425. 